\title{
ESTIMULACIÓN DE LA GERMINACIÓN Y DESARROLLO in vitro DE Laelia autumnalis CON RAYOS GAMMA
}

\author{
GAMMA RAY STIMULATION OF GERMINATION AND DEVELOPMENT \\ in vitro OF Laelia autumnalis
}

\author{
Selene Hernández-Muñoz ${ }^{1}$, Martha E. Pedraza-Santos ${ }^{1 *}$, Pedro A. López² , Eulogio De La Cruz- \\ Torres $^{3}$, Alejandro Martínez-Palacios ${ }^{4}$, Sylvia P. Fernández-Pavía ${ }^{4}$ y Ana T. Chávez-Bárcenas ${ }^{1}$
}

\begin{abstract}
'Facultad de Agrobiología "Presidente Juárez". Universidad Michoacana de San Nicolás de Hidalgo (UMSNH). Paseo de la Revolución esquina con Berlín. 60180, Col. Emiliano Zapata, Uruapan, Michoacán. Teléfono: 014525236474. ${ }^{2}$ Campus Puebla, Colegio de Postgraduados. Boulevard Forjadores de Puebla Núm. 205. 72760, Santiago Momoxpan, San Pedro Cholula, Puebla. ${ }^{3}$ Instituto Nacional de Investigaciones Nucleares. Ocoyoacac, Estado de México, México. ${ }^{4}$ Instituto de Investigaciones Agropecuarias y Forestales, UMSNH. km 9.5 Carretera Morelia-Zinapécuaro. 58880 , Tarímbaro, Mich.
\end{abstract}

*Autor para correspondencia (marelpesa@yahoo.com.mx)

\section{RESUMEN}

La germinación natural de las semillas de la orquídea $L$. autumnalis es baja, porque requiere condiciones específicas del árbol hospedero y factores ambientales favorables. La germinación asimbiótica in vitro es un método de propagación eficiente; sin embargo, el desarrollo de las plántulas requiere de uno a dos años. El objetivo fue evaluar el efecto de la radiación gamma ${ }^{60} \mathrm{Co}$ para estimular la germinación de semillas y el desarrollo in vitro de plántulas de $L$. autumnalis. Se irradiaron 22 frutos a diferentes dosis ( 3 a 30 Gy, con intervalos de $3 \mathrm{~Gy}$ ), además de un tratamiento sin irradiar utilizado como testigo. Las semillas se cultivaron en medio Murashige y Skoog sin fitohormonas. El diseño experimental fue completamente al azar con 16 a 32 repeticiones; la unidad experimental fue un frasco con $20 \mathrm{mg}$ de semillas. A los cinco días y posteriormente cada 10 días se cuantificó el número de semillas en las etapas de imbibición, formación de protocormos fotosintéticos, protocormos en diferenciación, desarrollo de promeristemos, hojas y plántulas. Se realizó un análisis de varianza y prueba de Tukey $(a=0.05)$. Las semillas irradiadas entre 3 y $15 \mathrm{~Gy}$ formaron $61 \%$ más protocormos fotosintéticos que las semillas sin tratar. Las semillas irradiadas con 3,15 y 18 Gy formaron $73 \%$ más promeristemos. Todos los protocormos tratados con 3 Gy formaron hojas 60 días después de la siembra (dds); en contraste, sólo $12.5 \%$ de las semillas no tratadas formaron hojas. El $66.5 \%$ de las semillas tratadas con 15 Gy desarrollaron plántulas a los 80 dds. Se confirmó el efecto radioestimulante de la radiación gamma a dosis bajas; con 3 Gy se formaron promeristemos, hojas y plántulas completas 20,20 y 10 días, respectivamente, antes que en el tratamiento control. La radiación a dosis superiores fue negativa al retrasar la germinación y el desarrollo de plántulas.

Palabras clave: Laelia autumnalis, cultivo in vitro, germinación asimbiótica, radiación gamma, radioestimulación.

\section{SUMMARY}

Natural seed germination of $L$. autumnalis orchid is low because it requires specific conditions of the host tree and favorable environmental factors. In vitro asymbiotic germination is an efficient propagation method; however, seedling development requires one to two years. The aim of this research was to evaluate the effect of ${ }^{60} \mathrm{Co}$ gamma radiation to stimulate in vitro germination and seedling development of $L$. autumnalis. Twenty-two fruits were irradiated at different doses ( 3 to $30 \mathrm{~Gy}$, with intervals of $3 \mathrm{~Gy}$ ), in addition to a non-irradiated treatment used as control. Seeds were cultured in Murashige and Skoog medium without phytohormones. The experimental design was completely randomized with 16 to 32 replications; the experimental unit was a flask with $20 \mathrm{mg}$ of seeds. At five days and then every 10 days the number of seeds in the stages of imbibition, photosynthetic protocorms formation, protocorms in differentiation, development of promeristems, leaves and seedlings was quantified. Analysis of variance and Tukey range test $(a=0.05)$ were performed. Seeds irradiated between 3 and $15 \mathrm{~Gy}$ formed $61 \%$ more photosynthetic protocorms than untreated seeds. Seeds irradiated with 3,15 and $18 \mathrm{~Gy}$ formed $73 \%$ more promeristems. All protocorms treated with $3 \mathrm{~Gy}$ formed leaves 60 days after sowing (das); in contrast, only $12.5 \%$ of untreated seeds formed leaves. About $66.5 \%$ of the seeds treated with $15 \mathrm{~Gy}$ developed seedlings at $80 \mathrm{das}$. The radiostimulating effect of gamma radiation was confirmed at low doses; with $3 \mathrm{~Gy}$ promeristems, leaves and complete seedlings were formed 20,20 and 10 days, respectively, earlier than the control treatment. Radiation at higher doses was negative by delaying germination and seedling development.

Index words: Laelia autumnalis, in vitro culture, asymbiotic germination, gamma radiation, radio stimulation.

\section{INTRODUCCIÓN}

Las orquídeas (Laelia autumnalis) son plantas de difícil reproducción natural porque sus semillas diminutas tienen escasa o nula reserva de nutrientes y requieren de la simbiosis con hongos micorrizógenos para su germinación, los cuales no siempre están presentes debido a la perturbación de su hábitat. Además, no todas las semillas de una cápsula se forman por completo o son fértiles (Verma et al., 2014). En muchos casos el embrión es pequeño con relación a la testa, por lo que hasta $96 \%$ del volumen de la semilla puede estar ocupado por aire, lo que dificulta que la humedad llegue al embrión (Arditti, 2008). En la germinación de algunas especies de orquídeas influye la concentración de ácido abscísico (ABA) presente en la semilla, de tal forma que existe una correlación negativa entre la concentración de ABA y el porcentaje de germinación (Lee et al., 2007); sumado a estas características, las semillas 
requieren de condiciones específicas del árbol hospedero y condiciones ambientales favorables (Pierik, 1990); debido a esto sólo germina el $1 \%$ de las semillas producidas (Verma et al., 2014), y de éstas, aproximadamente 0.4 plántulas por cada planta madre alcanzan la etapa reproductiva (Batty, 2001).

Las técnicas de cultivo in vitro han contribuido a mejorar la propagación de orquídeas a partir de semillas, tanto en especies nativas como en híbridos. En el género Laelia se ha logrado la germinación in vitro en L. speciosa (AguilarMorales y López-Escamilla, 2013), L. anceps ssp. dawsonii en la cual se logró la formación de embriones somáticos (Lee et al., 2010) y en L. eyermaniana donde se observó el desarrollo morfológico desde la germinación hasta la aclimatación ex vitro (Francisco et al., 2011).

En los casos anteriores el tiempo que transcurre entre la germinación y la obtención de plantas listas para aclimatar es hasta de dos años, lo que incrementa los costos en el manejo del material vegetal debido a los constantes ciclos de subcultivos necesarios para el adecuado desarrollo de las plántulas, por lo que es necesario desarrollar alternativas que permitan acortar este tiempo.

La combinación de las técnicas de cultivo in vitro con radiaciones ionizantes puede ser un método rápido y eficaz para incrementar y acelerar la germinación de las semillas. Cuando se emplean las radiaciones gamma en dosis bajas se estimula el proceso fisiológico de la germinación y el desarrollo de las plántulas (Araújo et al., 2016), también se acelera la proliferación de células, la actividad enzimática y el crecimiento celular (Chakravarty y Sen, 2001). En lechuga (Lactuca sativa var. capitata) los rayos gamma a dosis de 30 Gy (Gray) incrementaron $25 \%$ el porcentaje final de germinación y 75 \% el índice de germinación de las semillas (Marcu et al., 2013); además, en plantas de caupí (Vigna sinensis) generadas a partir de semillas irradiadas con 5 krad (50 Gy) de rayos gamma se incrementó la longitud de brotes y raíces y la producción de biomasa en condiciones salinas (Mohammed et al., 2012).

En semillas de sándalo rojo (Pterocarpus santalinus) irradiadas con 50 Gy la germinación fue más del doble (51 \%) que en el tratamiento control (23\%), y una velocidad de germinación mayor se presentó en las semillas tratadas con 25 Gy (Akshatha y Chandrashekar, 2013). Al evaluar la radiosensibilidad de semillas de estevia (Stevia rebaudiana) cultivar KH-IAN VC-142 (Eireté), con dosis de 10 a 90 Gy, se observó que la dosis de 10 Gy estimuló la geminación de semillas en $52 \%$, es decir 33 \% más que el control (González y Nacayama, 2015). En semillas de arjuna (Terminalia arjuna) con dosis de 25, 50 y 100 Gy se duplicó el porcentaje de germinación (34 \%) en compara- ción con el testigo (16\%). Un número mayor de hojas (12) se observó con las dosis de 100 y 200 Gy y un mayor peso seco se registró con las dosis de 25 y 50 Gy (1.04 y $0.93 \mathrm{~g}$, respectivamente) (Akshatha et al., 2013).

En la orquídea L. autumnalis no existen reportes del efecto de la radiación gamma sobre su germinación. Esta especie es originaria de México, presenta flores atractivas color magenta; además, tiene potencial ornamental para usarse como planta para flor de corte o para cultivo en macetas. Las laelias, aunque se propagan con éxito a partir de semillas germinadas in vitro, el periodo para el desarrollo de plantas listas para aclimatarse en invernadero es largo, por lo menos de dos años (Aguilar-Morales y LópezEscamilla, 2013). La implementación de estrategias que aceleren el desarrollo de esta especie es una condición importante para su conservación natural o explotación a nivel comercial. Por lo anterior, el objetivo de esta investigación fue estudiar el efecto de la irradiación gamma ${ }^{60} \mathrm{Co}$ sobre la germinación y desarrollo in vitro de L. autumnalis. La hipótesis fue que la radiación gamma ${ }^{60} \mathrm{Co}$ en dosis bajas estimula la germinación y desarrollo in vitro de semillas de la orquídea L. autumnalis.

\section{MATERIALES Y MÉTODOS}

Se utilizaron 22 frutos (cápsulas) de plantas de Laelia autumnalis, provenientes de la colección del Banco de Germoplasma del Sistema Nacional de Recursos Fitogenéticos.

\section{Irradiación con rayos gamma ${ }^{60} \mathrm{Co}$}

Las cápsulas se irradiaron con rayos gamma ${ }^{60} \mathrm{Co}$ a 10 dosis $(3,6,9,12,15,18,21,24,27$ y 30 Gy), con un irradiador Gammacell 220 (Hungría), en el Departamento del Irradiador Gamma del Instituto Nacional de Investigaciones Nucleares (ININ), además de un tratamiento testigo sin irradiar.

\section{Medio de cultivo}

Se utilizó el medio de cultivo Murashige y Skoog (1962) (MS), sin fitohormonas y adicionado con sacarosa (30 g $\left.\mathrm{L}^{-1}\right)$, mioinositol (100 $\left.\mathrm{mg} \mathrm{L}^{-1}\right)$, tiamina $\left(0.4 \mathrm{mg} \mathrm{L}^{-1}\right)$ y agar $(6$ $\left.\mathrm{g} \mathrm{L}^{-1}\right)$, el pH se ajustó a $5.7 \pm 0.1$ con $\mathrm{NaOH} 1 \mathrm{~N}$. Se vertieron $20 \mathrm{~mL}$ de medio en frascos de vidrio de $100 \mathrm{~mL}$ de capacidad y se esterilizaron en autoclave durante $15 \mathrm{~min}$ a $1.2 \mathrm{~kg}$ $\mathrm{cm}^{-2}$ de presión y $121^{\circ} \mathrm{C}$.

\section{Establecimiento del cultivo aséptico}

Las 22 cápsulas irradiadas (dos frutos por cada dosis de irradiación más dos frutos del testigo) se lavaron con agua 
y detergente, y se desinfectaron con hipoclorito de sodio comercial $60 \%$ v/v (6 \% de ingrediente activo) durante 20 min. En una campana de flujo laminar se retiró la solución desinfectante y se hicieron tres enjuagues con agua estéril. Las cápsulas se abrieron con bisturí y se colocaron aproximadamente $20 \mathrm{mg}$ de semilla por frasco con medio de cultivo. La incubación se efectuó a $25^{\circ} \mathrm{C}$ con fotoperiodo de 16/8 h luz/oscuridad y radiación fotosintéticamente activa de $45 \mu \mathrm{E} \mathrm{m}^{-2} \mathrm{~s}^{-1}$ proporcionada por lámparas de luz fluorescente blanca de $75 \mathrm{~W}$. Se utilizó un diseño experimental completamente al azar con 11 tratamientos y 16 a 32 repeticiones. El número de repeticiones varió en función de la cantidad de semillas contenidas en cada cápsula. La unidad experimental fue cada uno de los frascos con 20 mg de semillas (entre 500 y 700 semillas).

\section{Variables evaluadas}

A los 5 días después de la siembra (dds), y posteriormente cada $10 \mathrm{~d}$, se seleccionaron tres áreas de $1 \mathrm{~cm}^{2}$ en cada frasco de cultivo y mediante observación en un microscopio estereoscópico marca Leica S6D (Alemania) se cuantificó el número total de semillas en las etapas de germinación (imbibición, formación de protocormos fotosintéticos, protocormos en diferenciación y desarrollo de promeristemos), formación de hojas y formación de plántulas. Con la suma de semillas en cada etapa fenológica se obtuvo el número total de semillas en $1 \mathrm{~cm}^{2}$, que se usó como denominador para obtener el porcentaje de imbibición (IM) de la siguiente forma: IM = (Número de semillas imbibidas/Número total de semillas en $\left.1 \mathrm{~cm}^{2}\right) \times 100$. En las variables formación de protocormos fotosintéticos (FPF), protocormos en diferenciación (PD), desarrollo de promeristemos (DP), formación de hojas (FH) y plántulas (FP) se utilizó el mismo procedimiento.

La velocidad de imbibición (VIM), de formación de protocormos fotosintéticos (VFPF), protocormos en diferenciación (VPD), desarrollo de promeristemos (VDP), formación de hojas (VFH) y de formación de plántulas (VFP), se calcularon al dividir el porcentaje máximo de semillas en cada etapa fenológica entre el número de días que las semillas requirieron para obtener ese porcentaje, de acuerdo con la fórmula propuesta por González-Zertuche y OrozcoSegovia (1996).

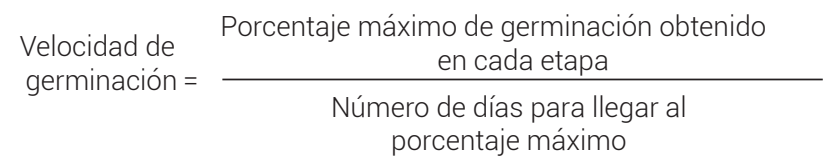

\section{Análisis estadístico}

Los datos de las variables respuesta obtenidos en por- centajes se normalizaron mediante transformación a raíz cuadrada más uno y se procesaron mediante un análisis de varianza con el procedimiento GLM y se utilizó la prueba de Tukey $(a=0.05)$ para la comparación de medias entre tratamientos. El análisis estadístico se realizó con el programa SAS versión 9.0 (SAS Institute, 2002).

\section{RESULTADOS Y DISCUSIÓN}

\section{Fenología de la germinación in vitro de semillas irradiadas de $L$. autumnalis}

El proceso de imbibición se presentó entre 5 y 40 dds. En esta etapa las semillas tuvieron un incremento aproximado de 50 \% en su tamaño, el embrión se observó de color amarillo claro, con forma globosa, y se separó de la testa para formar una estructura globular compacta y translúcida (Figura 1A). Este incremento de tamaño fue ocasionado por la absorción de agua, fenómeno que se ha documentado en semillas de orquídeas como Chloraea crispa (Verdugo et al., 2007), Oncidium longicornu, O. bifolium (Billard et al., 2014) y L. speciosa (Aguilar-Morales y López-Escamilla, 2013), en las cuales la germinación inició a los 6, 4, 6 y 10 días, respectivamente.

Este proceso de imbibición asincrónica presentado en L. autumnalis se ha reportado en otras especies de orquídeas como L. speciosa, donde la imbibición inició a los 10, 16, 114 y 178 dds en los medios MS al 50 \%, MS $100 \%$, KC (Knudson C) al $50 \%$ y KC al $100 \%$, respectivamente (Aguilar-Morales y López-Escamilla, 2013). La imbibición asincrónica puede ser atribuida a la permeabilidad inconsistente de las testas, por las grietas secas que a menudo se presentan en las semillas de las orquídeas epífitas (VanWaes y Debergh, 1986); además, la testa puede contener suberina la cual contribuye a la impermeabilidad (Kauth et al., 2008). Durante la maduración de la semilla se forma una capa de cutina y lignina en el tegumento interno que puede servir para reforzar la testa; sin embargo, entre más ajustado esté el embrión por la testa, mayor es la inhibición del crecimiento de éste por restricción mecánica o química (Yamazaki y Miyoshi, 2006).

La formación de protocormos fotosintéticos (FPF) inició a los 10 dds y concluyó hasta los 60 dds (Figura 2). Esta fase se caracterizó por el cambio de color del embrión de blanco y amarillo claro, a verde (Figura 1B). La formación de protocormos diferenciados (FPD) inició a los 20 y concluyó a los 70 dds (Figura 2). En esta etapa los protocormos incrementaron su longitud y circunferencia, y se intensificó la coloración verde como se aprecia en la Figura 1C, la cual indica la presencia de clorofila y por lo tanto de cloroplastos (Francisco et al., 2011). 


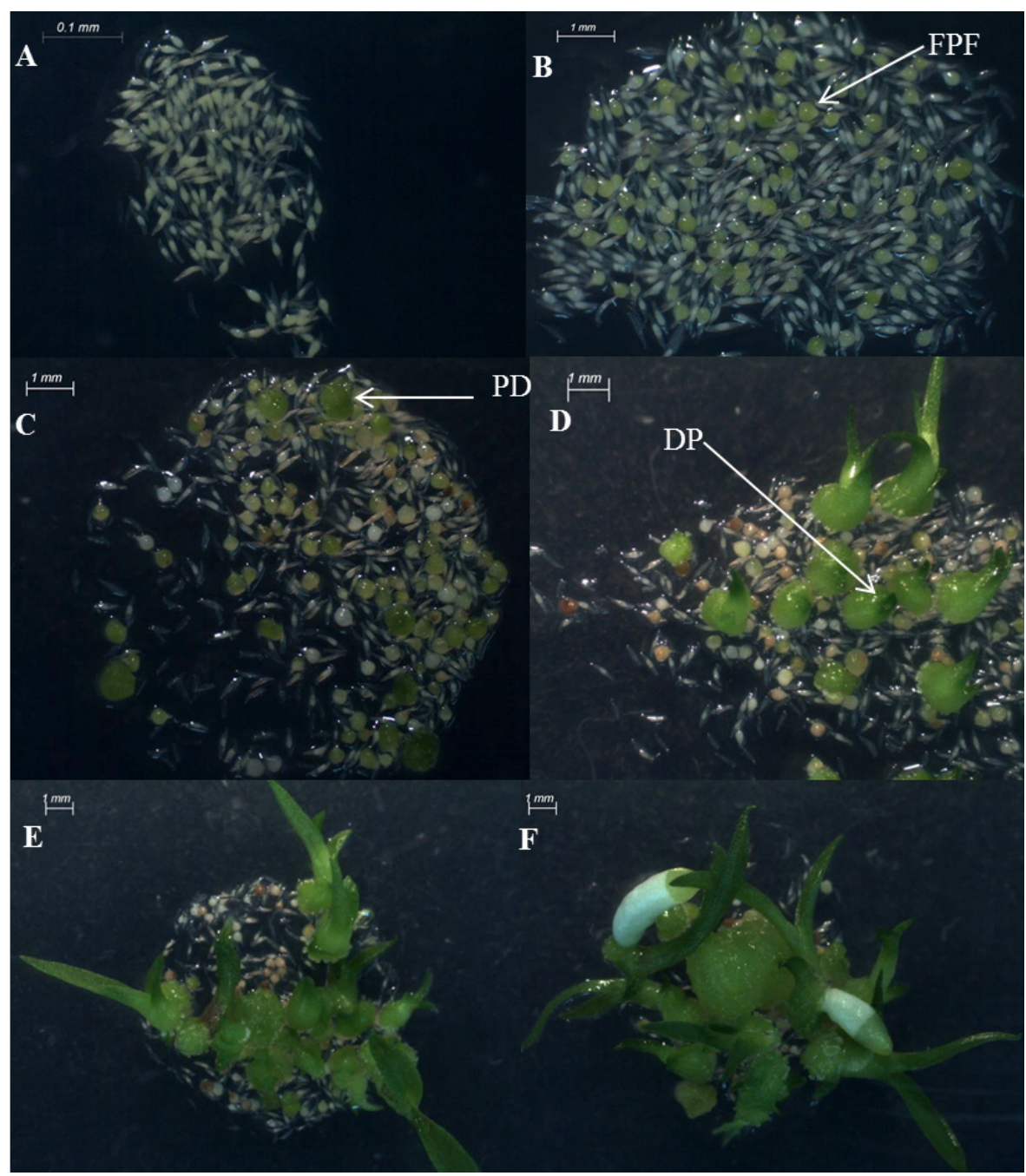

Figura 1. Etapas fenológicas en la germinación de semillas de Laelia autumnalis A) imbibición, B) protocormos fotosintéticos (FPF), C) protocormos en diferenciación (PD), D) desarrollo de promeristemos (DP), E) formación de hojas y F) formación de plántulas.

La etapa fenológica de desarrollo de promeristemos (DP) se observó a partir de los 30 y hasta los 90 dds (Figura 2). Esta fase inició cuando en los protocormos se formó un complejo de células meristemáticas de color verde, el cual dio origen al primordio foliar (Figura 1C). En L. especiosa se reportan cambios similares en esta etapa a los 202 dds, a la cual denominan protocormo inicial (Aguilar-Morales y López-Escamilla, 2013).

La formación de hojas (FH) ocurrió a los 40 dds y concluyó a los 110 dds (Figura 2), y se originaron del protocormo (Figura 1D). La formación de plántulas (FP) se presentó entre los 70 y 120 dds (Figura 2). Esta fase inició con el desarrollo de raíces, cuyo primordio se desarrolló cerca de la base de las hojas y las raíces se observaron de color blanco con el ápice verde.

\section{Efecto de la irradiación gamma ${ }^{60} \mathrm{Co}$ sobre la germinación de semillas in vitro}

La radiación mostró un efecto significativo en la germinación y el desarrollo de las plántulas. En la etapa inicial (5 dds), las semillas sin irradiar fueron las primeras en llegar a $100 \%$ de imbibición (IM), estadísticamente similares a las semillas tratadas con 3, 6 y 12 Gy que presentaron 73 , 85 y $57 \%$ de semillas hidratadas. Conforme se incrementó la dosis de radiación se redujo la IM (Figura 3A) y en las dosis de 24 y 30 Gy las semillas iniciaron este proceso a los 10 dds (Figura 3B). Entre los 20 y 30 dds la totalidad de las semillas presentaron $100 \%$ de IM, excepto aquellas tratadas con 24 y 30 Gy que registraron 72.5 y 82 \% (Figura 3C). La dosis de irradiación aplicada influyó en la duración de la etapa de absorción de agua. Las semillas tratadas con 


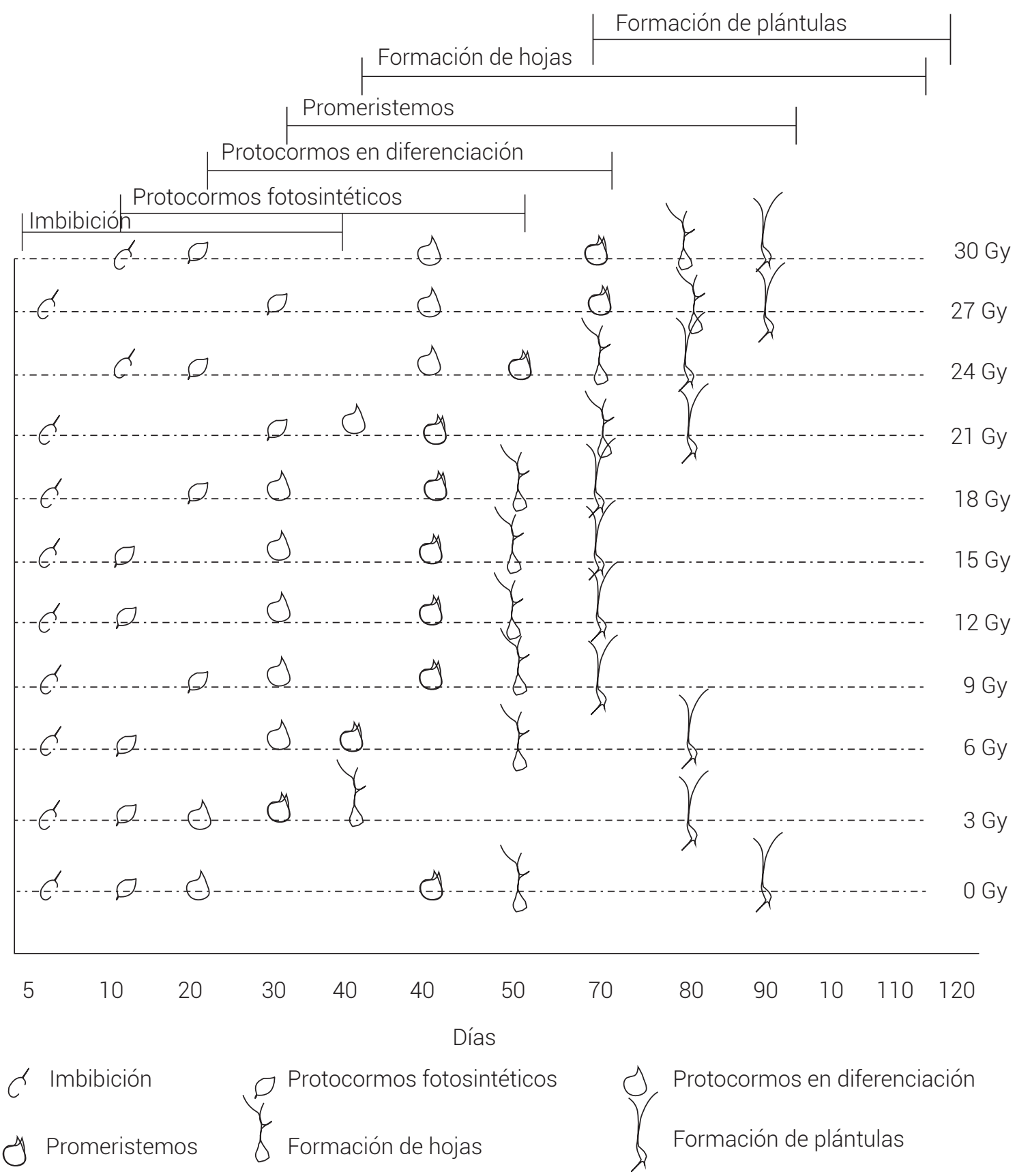

Figura 2. Fenología de la germinación de semillas, formación de hojas y plántulas de Laelia autumnalis irradiadas con rayos gamma de 3 a $30 \mathrm{~Gy}$ y un testigo sin irradiar. Las figuras marcan el inicio de cada etapa y las líneas de la parte superior indican el inicio y final de cada etapa.

30 Gy tardaron 35 d más que las semillas no irradiadas. La mayor velocidad de absorción por día se presentó con el tratamiento sin irradiar (20\%), estadísticamente similar a la dosis de 6 Gy $(17.5 \%)$, pero superior a las semillas irradiadas con dosis de 9 a $30 \mathrm{~Gy}$, que presentaron menos del $10 \%$ de IM por día (Figura 3D).

La imbibición es un fenómeno físico y puede presentar- se aun en semillas con embriones muertos. La absorción inicial implica la retención de agua por coloides, lo que suaviza las cubiertas de la semilla e hidrata al protoplasma, provoca el hinchamiento y el posible rompimiento de las cubiertas (Hartmann et al., 2010); sin embargo, el efecto de la radiación sobre la imbibición de las semillas puede ser atribuido al contenido de humedad en las semillas, ya que la radiación interactúa con las moléculas del agua para 

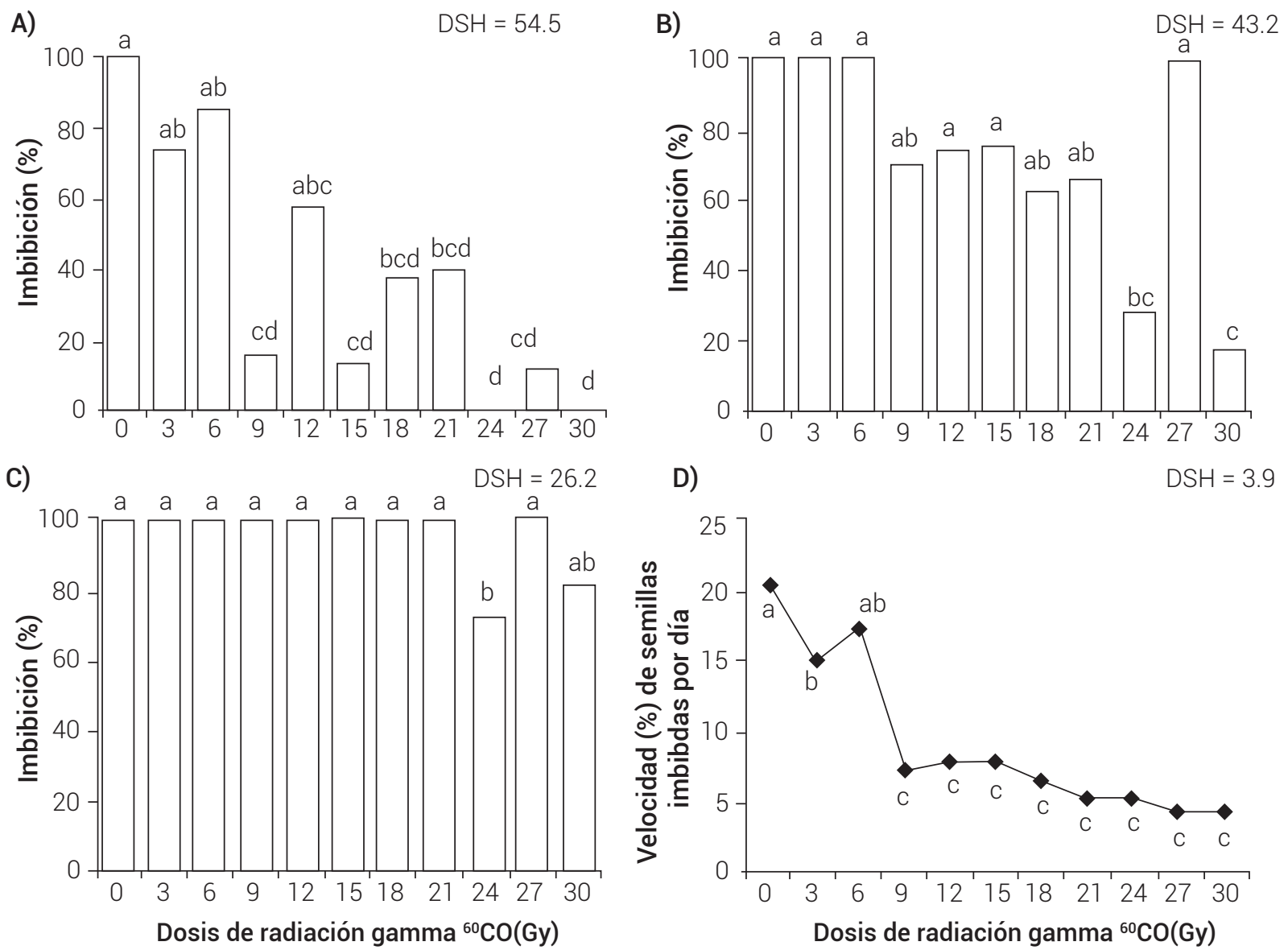

Figura 3. Efecto de la irradiación gamma ${ }^{60} \mathrm{Co}$ sobre la imbibición in vitro de semillas de L. autumnalis. A) 5 días después de la siembra (dds), B) 10 dds, C) 20 dds y 30 dds. D) velocidad de imbibición de semillas. Medias con letras iguales no son estadísticamente diferentes (Tukey, 0.05).

producir radicales libres en las células y el efecto varía en función de la dosis de radiación (El-Fiki et al., 2015).

La formación de protocormos fotosintéticos (FPF) se presentó a partir de los 10 dds en las dosis menores a 15 Gy, excepto en la dosis de 9 Gy. El máximo porcentaje (49 $\%)$ se registró en la dosis de $3 \mathrm{~Gy}$, estadísticamente similar al obtenido en semillas tratadas con 6 Gy (28.5 \%) (Figura 4A). Las semillas irradiadas con 3 a 15 Gy presentaron mayor FPF, superiores $61 \%$ a lo obtenido en las semillas sin irradiar (Figura 4B) a los 20 dds, por lo que estas dosis tienen un efecto radioestimulante. A los 30 dds se tuvo un efecto inhibitorio en las semillas tratadas con la dosis de 24 a 30 Gy en las que se presentó cinco veces menos FPF en comparación con las semillas no irradiadas (Figura 4C); este efecto negativo continuó hasta los 40 dds ya que las semillas irradiadas con 27 y 30 Gy presentaron 43 y $45.5 \%$ FPF (Figura 4D).

La mayor velocidad de formación de protocormos fotosintéticos (VFPF) por día se tuvo en las dosis de 3 a 15
Gy (2.3\% más que el control) (Figura 4E), lo que indica un efecto estimulante de la radiación sobre esta variable. La radioestimulación de las semillas a dosis bajas de radiaciones es atribuida al incremento en la absorción de oxígeno, lo que genera producción de radicales orgánicos e inorgánicos de peróxido, que ocasionan la ruptura de la latencia de las semillas (Minisi et al., 2013); además, la radiación ionizante actúa como disparador o impulsor del desarrollo, intensifica la actividad de las enzimas hidrolíticas y provoca un incremento en la velocidad de conversión de los sustratos respiratorios en pequeñas moléculas, a partir de las cuales se forman los nuevos constituyentes celulares que dan origen a la plántula (Álvarez et al., 2012).

A los 30 dds la totalidad de las semillas sin irradiar alcanzaron la etapa de formación de protocormos diferenciados (FPD), de forma estadísticamente similar a las semillas irradiadas entre 3 y 9 Gy (73\% en promedio), y superior a las semillas tratadas con dosis entre 15 y 30 Gy (5\% en promedio) (Figura 5A). Este efecto negativo de la radiación en las dosis altas continuó a los 40 dds en los subcultivos 


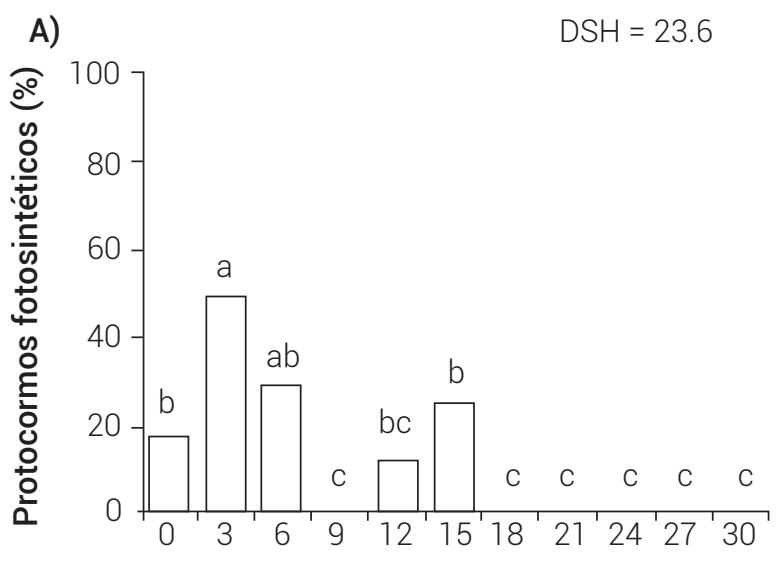

B)

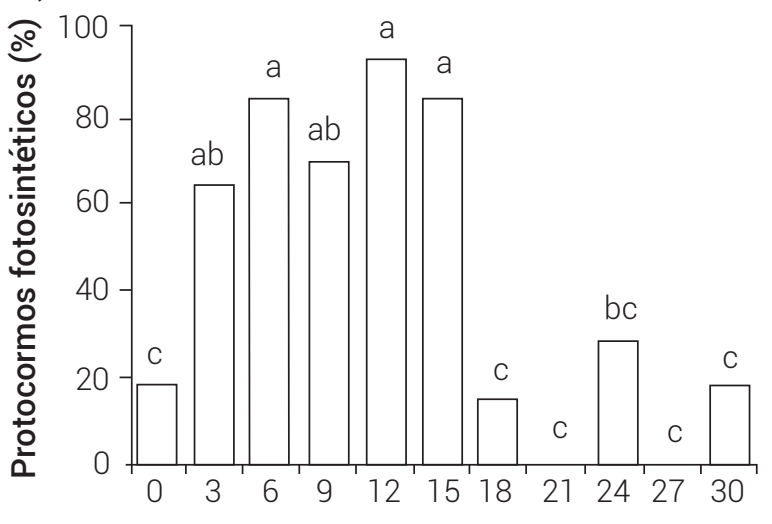

C)

$\mathrm{DSH}=57.2$
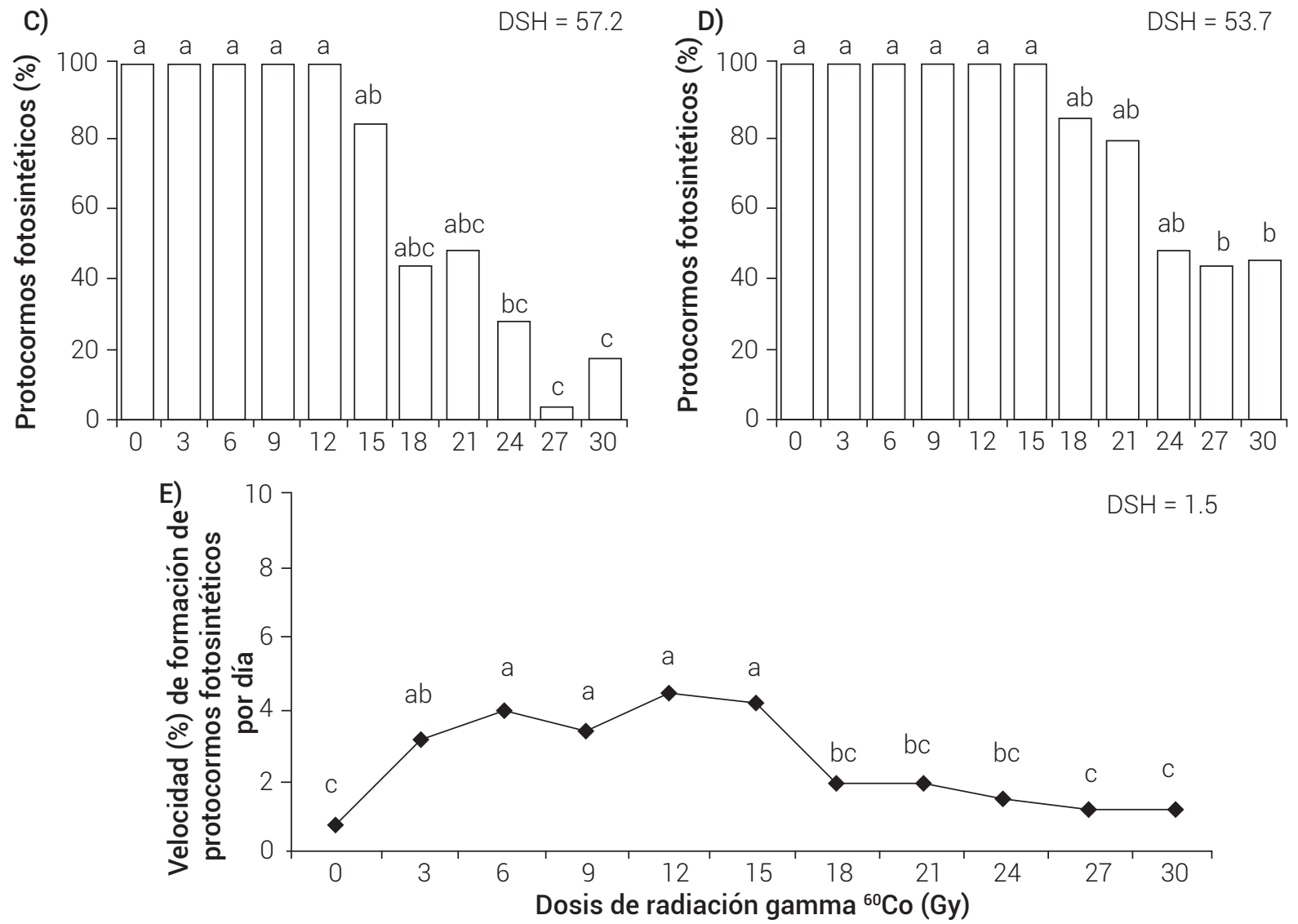

Figura 4. Efecto de la irradiación gamma ${ }^{60} \mathrm{Co}$ sobre la formación de protocormos fotosintéticos in vitro a partir de semillas de L. autumnalis. A) 10 días después de la siembra (dds), B) 20 dds, C) 30 dds y D) 40 dds, E) velocidad de formación de protocormos fotosintéticos. Medias con letras iguales no son estadísticamente diferentes (Tukey, 0.05).

tratados con 18 a 30 Gy (6\%) (Figura 5B), así como a los 50 dds en las semillas irradiadas con dosis de 21 a 30 Gy (44 $\%$ en promedio) (Figura 5C). En las semillas tratadas con 24 a 30 Gy el proceso de FPD fue más sincronizado y tomó $20 \mathrm{~d}$ (Figuras 5C y 5D).

La velocidad de protocormos diferenciados (VPD) por día fue mayor en semillas sin irradiar (3.33\%), estadísti- camente similar a las semillas irradiadas con 3, 9 y 12 Gy. Se observó una tendencia a disminuir VDP conforme se aumentó la dosis de radiación. El menor porcentaje (0.73 $\%)$ se presentó en semillas irradiadas con 18 Gy, valor estadísticamente similar a los obtenidos con las dosis de 21 a 30 Gy (Figura 5E). Estos resultados se pueden explicar porque dosis altas de radiación causan daños severos en el ADN; sin embargo, algunas células tienden a recuperarse 

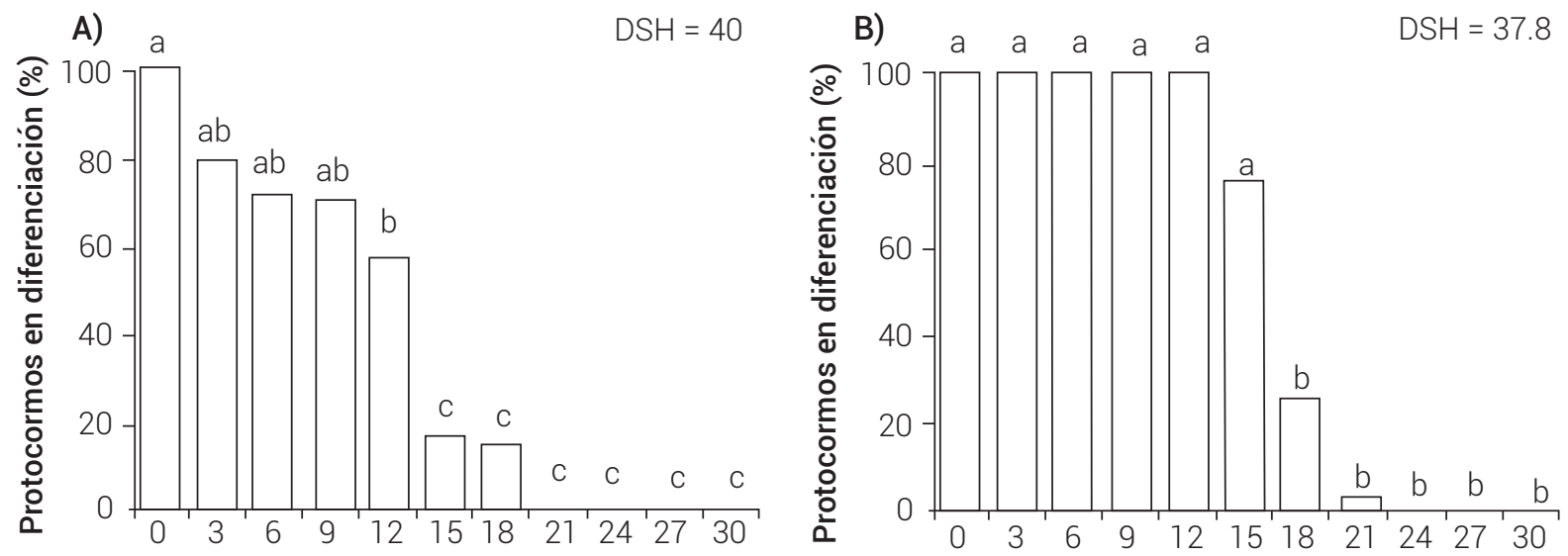

C)

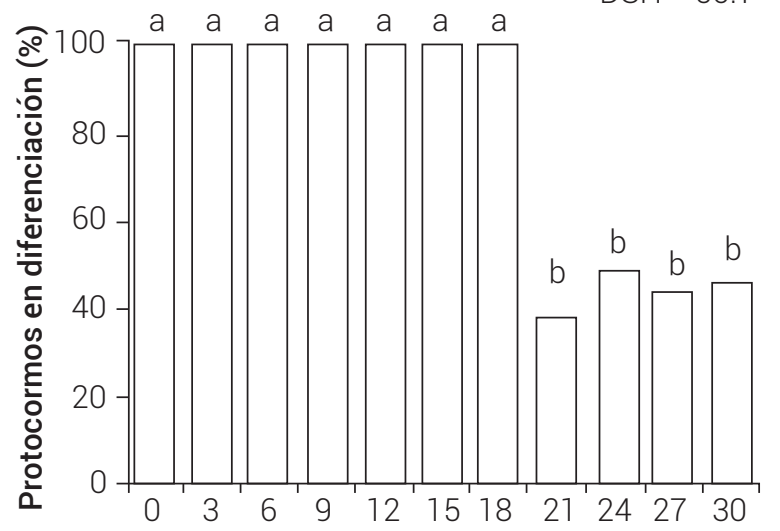

D)

$\mathrm{DSH}=27.7$
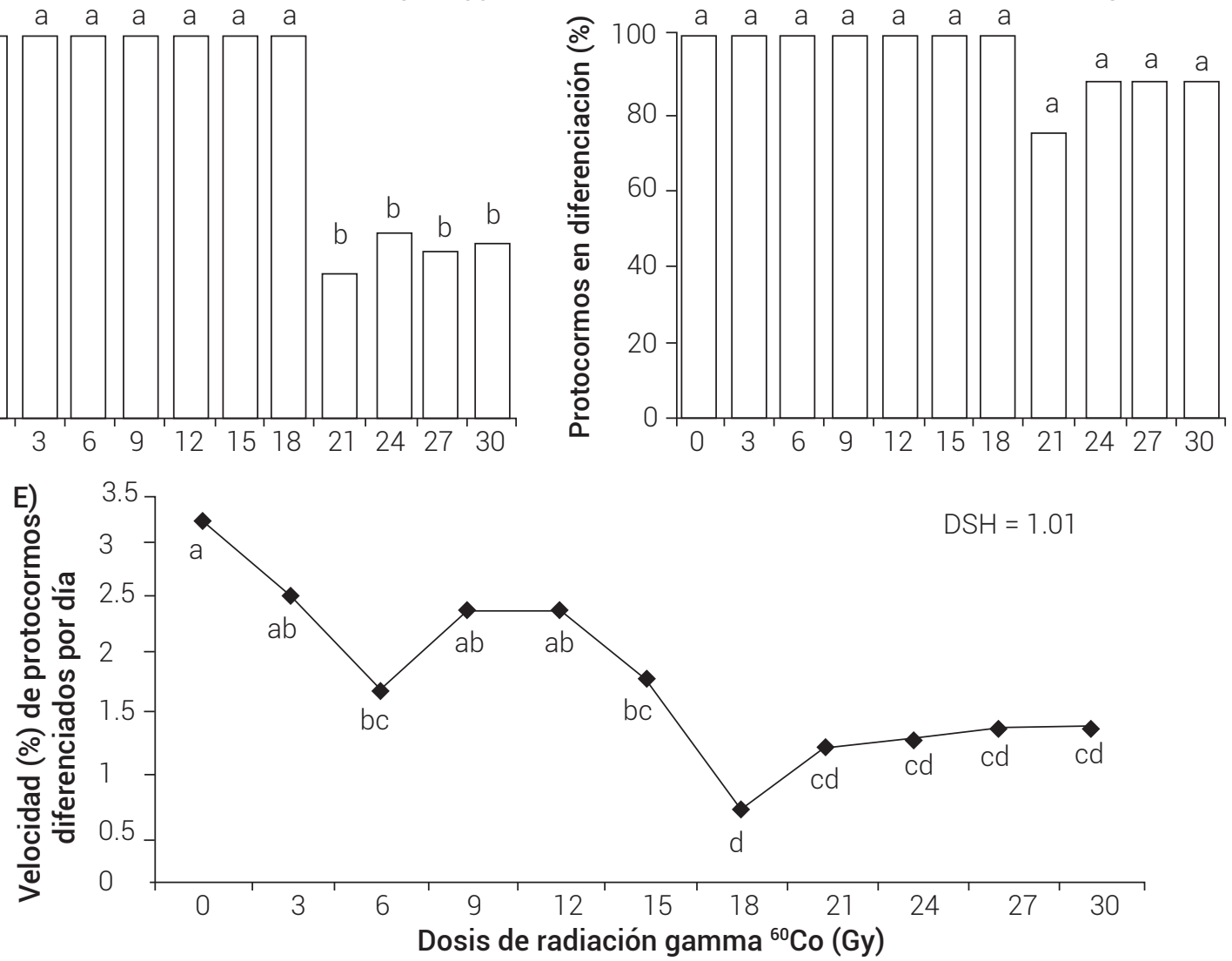

Figura 5. Efecto de la irradiación gamma ${ }^{60} \mathrm{Co}$ sobre la diferenciación de protocormos in vitro a partir de semillas de $L$. autumnalis. A) 30 días después de la siembra (dds), B) 40 dds, C) 50 dds y D) 60 dds. E) velocidad de formación de protocormos en diferenciación. Medias con letras iguales no son estadísticamente diferentes (Tukey, 0.05).

de cuatro a ocho semanas después de la radiación (Lee et al., 2016).

En el desarrollo de promeristemos (DP) se presentó un efecto estimulante en las semillas irradiadas con 3, 15 y 18 Gy, que en promedio presentaron 73 \% más formación de promeristemos que las semillas sin irradiar (Figura 6A). En los cultivos tratados con las dosis más altas (27 y 30 Gy) se inhibió el DP hasta los 60 dds (Figura 6B); sin embargo, a los 70 dds incrementó significativamente (71 y $77.5 \%$ ) en ambas dosis de radiación (Figura 6C); el menor porcentaje (66\%) a los 80 dds se obtuvo en las semillas tratadas con $24 \mathrm{~Gy}$, estadísticamente similares a las semillas irradiadas con 27 Gy (80 \%) (Figura 6D).

La velocidad de desarrollo de promeristemos (VDP) se 

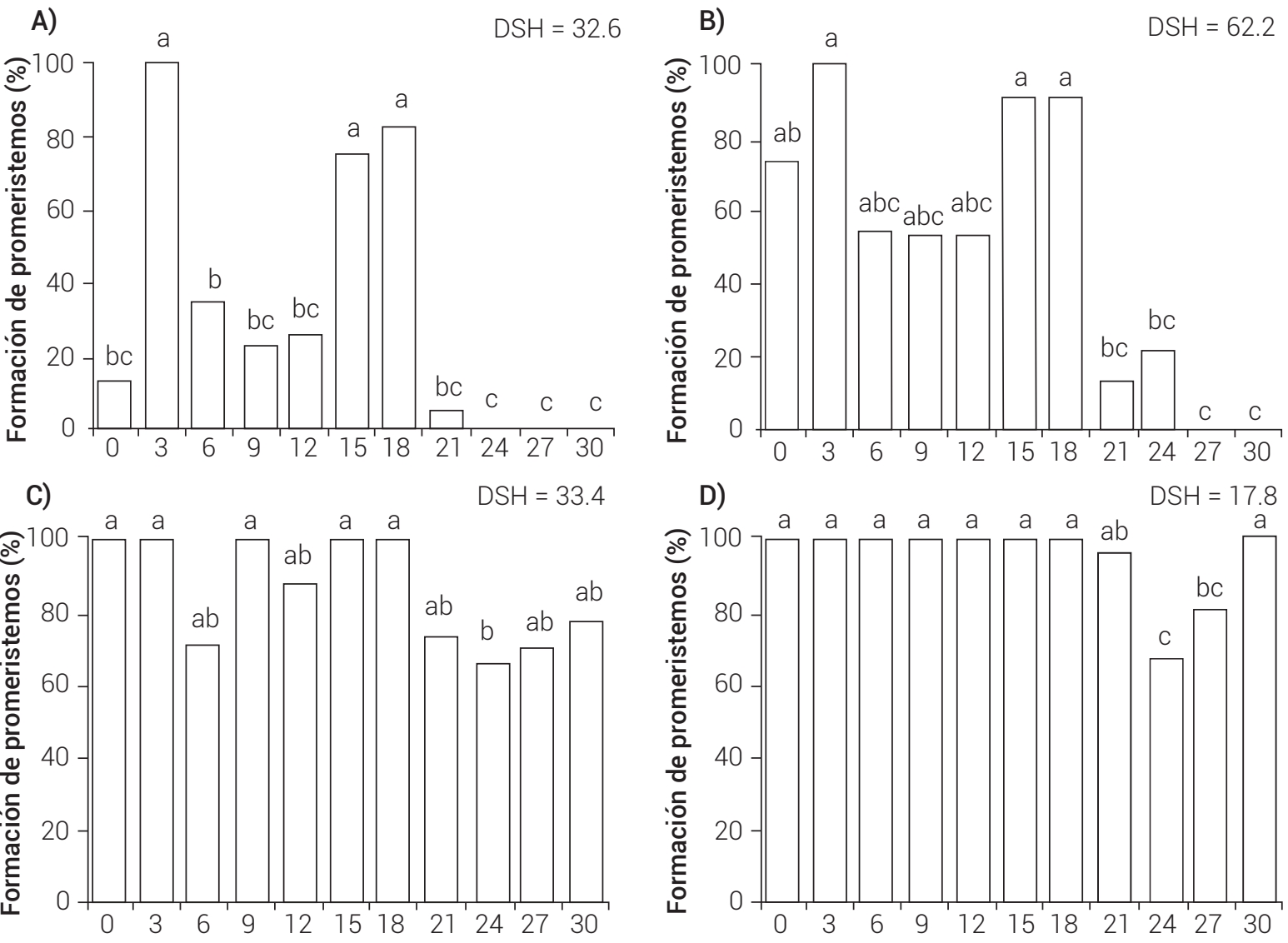

D)
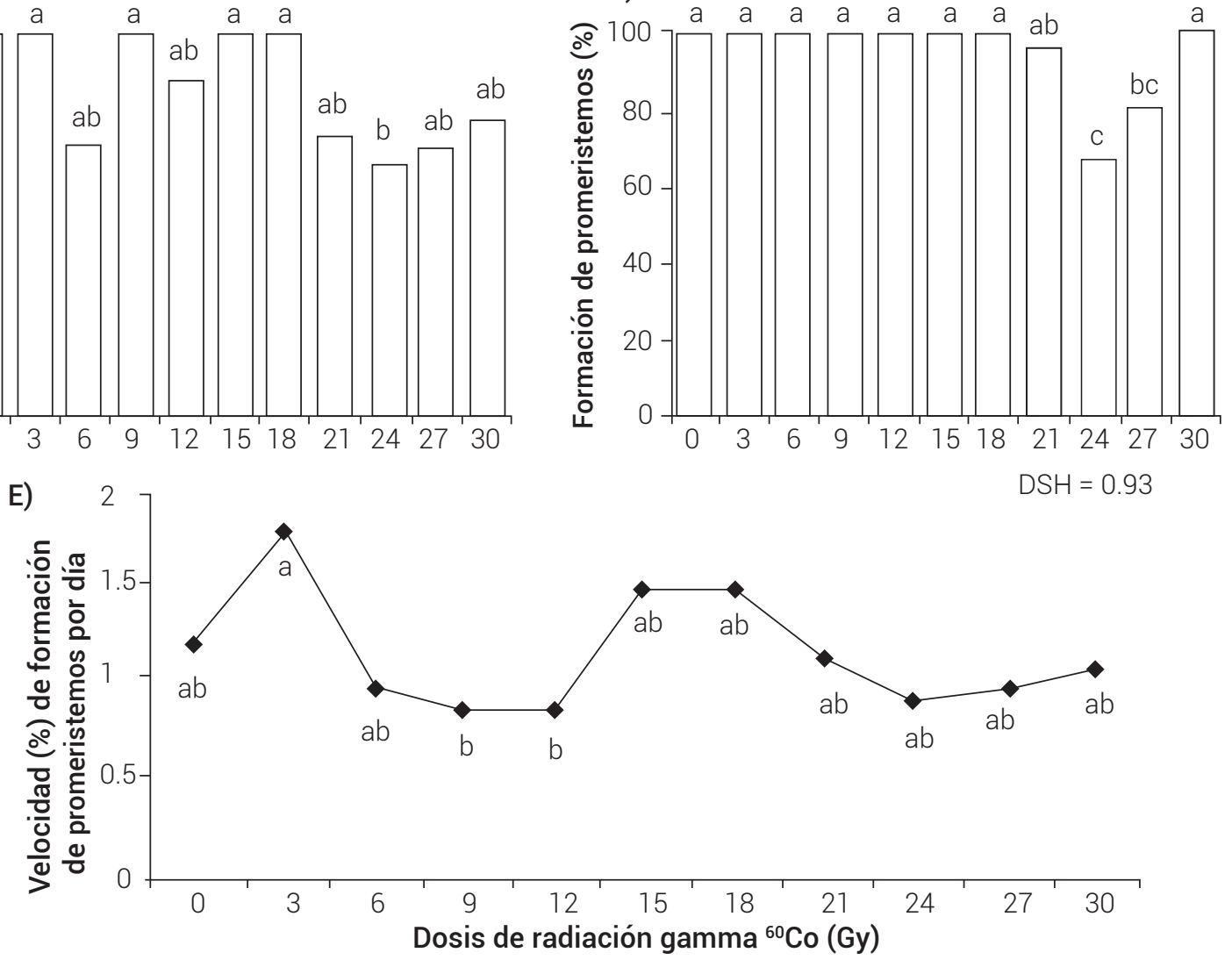

Figura 6. Efecto de la irradiación gamma ${ }^{60} \mathrm{Co}$ sobre la formación de promeristemos in vitro a partir de semillas de $L$. autumnalis. A) 50 días después de la siembra (dds), B) 60 dds, C) 70 dds y D) 80 dds. E) velocidad en la formación de promeristemos. Medias con letras iguales no son estadísticamente diferentes (Tukey, 0.05).

aceleró con la dosis de 3 Gy (1.83\%), estadísticamente superior a las semillas tratadas con dosis de 9 y 12 Gy, que presentaron $0.88 \%$ de formación de promeristemos por día, pero estadísticamente igual al resto de los tratamientos (Figura 6D). El efecto estimulante observado con la dosis de 3 Gy se puede deber a la excitación que producen las radiaciones ionizantes a dosis bajas en las semillas, las cuales estimulan su metabolismo y favorece el crecimien- to y desarrollo de las plántulas (Álvarez et al., 2013). Otra de las causas de estimulación de los rayos gamma sobre la germinación se ha atribuido a la activación de ARN o síntesis de proteínas, que se produce durante la primera etapa de germinación en las semillas después de la irradiación (Kumar et al., 2013).

La formación de hojas (FH) en la totalidad del tratamiento 
irradiado con dosis de 3 Gy se observó a los 60 dds, en comparación con las semillas no tratadas en las cuales solo $12.5 \%$ de los protocormos formaron hojas (Figura 7A). A los 70 dds, las dosis de 6, 12 y 21 a 30 Gy presentaron $67 \%$ menos de protocormos con hojas que el tratamiento control (Figura 7B); mientras que a los 80 dds fue visible la tendencia de retardo en la FH conforme se incrementó la dosis de radiación, las semillas irradiadas con 21 y 27 Gy presentaron el menor porcentaje (16.5\%) (Figura 7C). En las dosis de 27 y 30 Gy continuó el efecto negativo de la radiación a los 90 dds, en ambas dosis se redujo 60 \% la FH con respecto al control (Figura 7D).

La mayor velocidad de formación de hojas (VFH) por día se presentó en las semillas irradiadas con 3 Gy $(1.43 \%)$, valor estadísticamente similar al de las semillas sin irradiar (1.25\%) y a las tratadas con 18 Gy $(0.97 \%)$, pero superior al de las semillas tratadas con 6 a 15 y 21 a 30 Gy (Figura
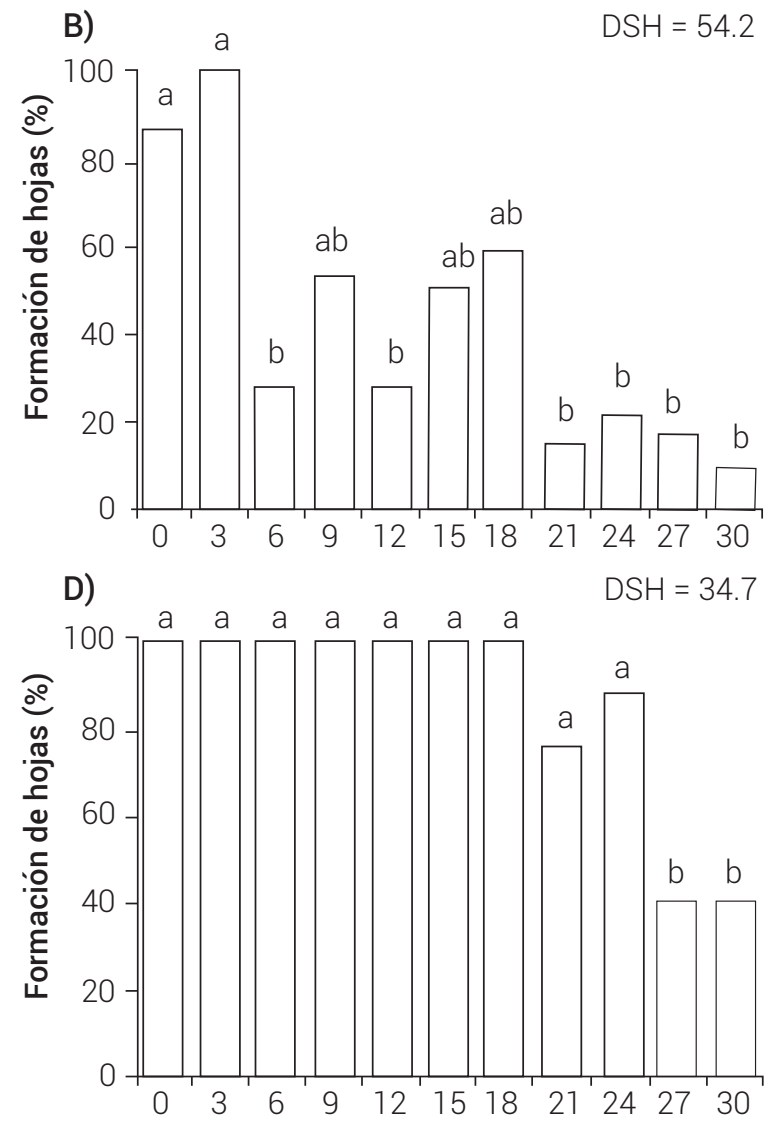
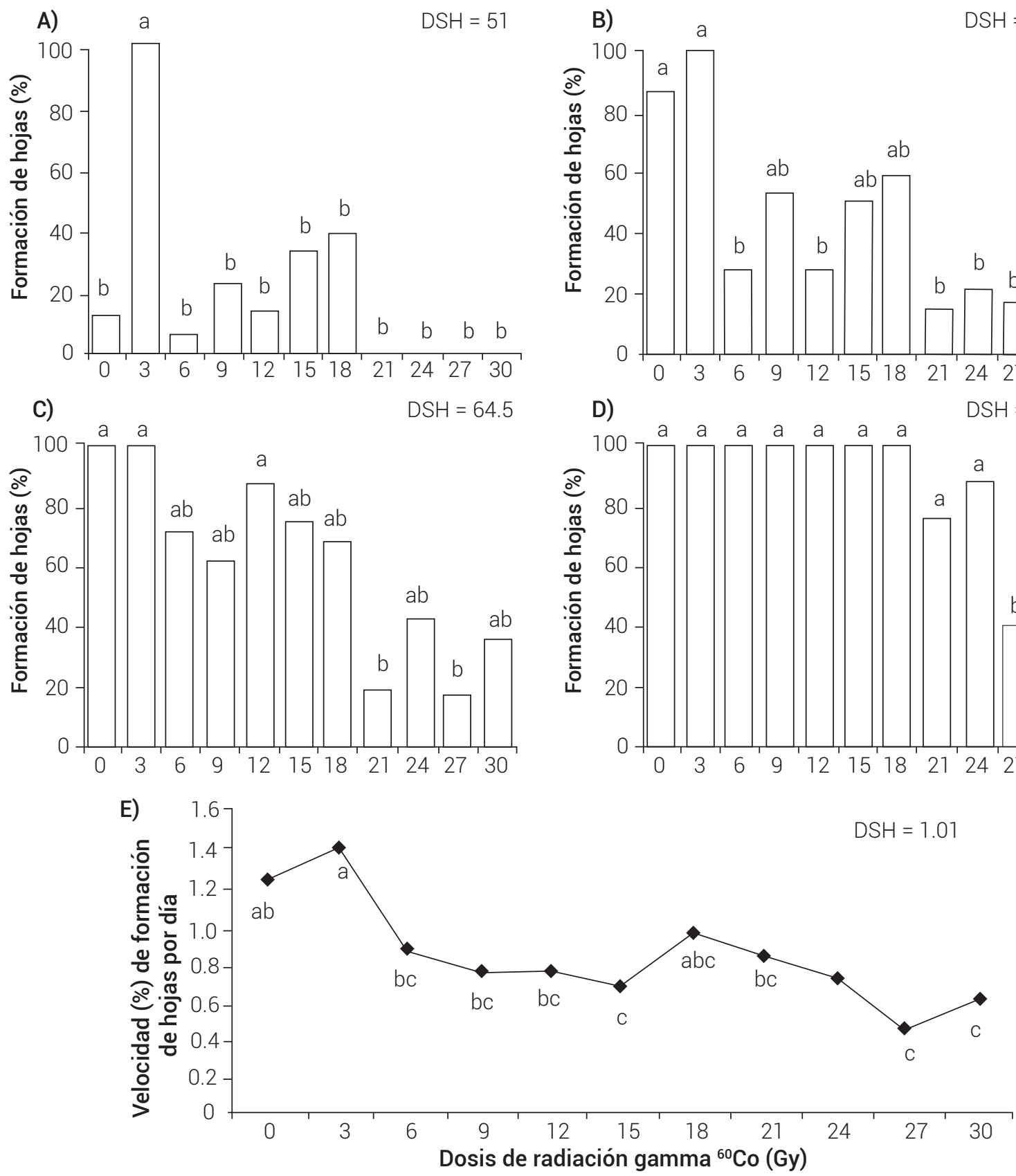

Figura 7. Efecto de la irradiación gamma ${ }^{60} \mathrm{Co}$ sobre la formación de hojas en protocormos in vitro a partir de semillas de $L$. autumnalis. A) 60 días después de la siembra (dds), B) 70 dds, C) 80 dds y D) 90 dds. E) velocidad de formación de hojas en protocormos. Medias con letras iguales no son estadísticamente diferentes (Tukey, 0.05). 
7E). Algunos autores relacionan el efecto estimulante de las bajas dosis de radiación con la activación de enzimas como las polifenoloxidasas, catalasas, peroxidasas y esterasas, las cuales conllevan a la formación de sustancias fisiológicamente activas que a bajas concentraciones aceleran la división celular, conjuntamente con la morfogénesis en las células, mitocondrias y los cloroplastos (Cwintal y Olszewski, 2007).
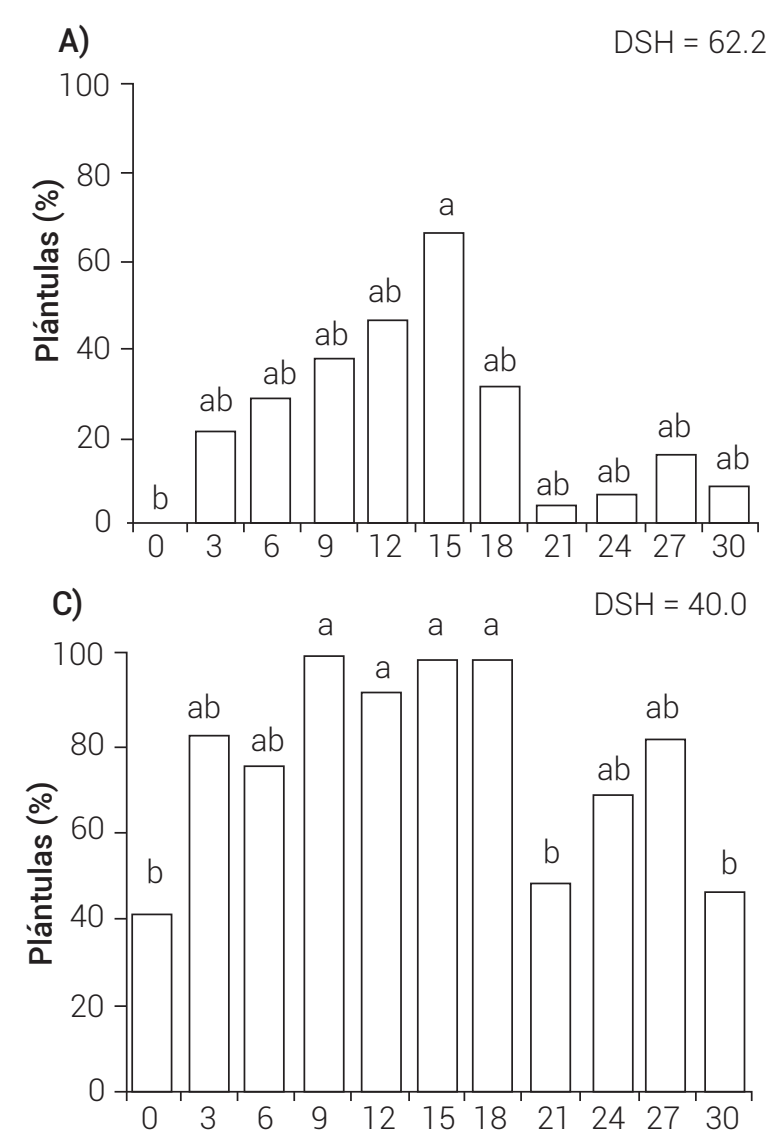

La radiación estimuló la emergencia de raíces y por lo tanto la formación de plántulas (FP). Las semillas tratadas con 15 Gy presentaron el mayor porcentaje $(66.5 \%)$ a los 80 dds, valor estadísticamente similar al resto de las semillas irradiadas, pero superior al de las semillas sin irradiar (Figura 8A). En las semillas tratadas con 12 Gy se observó que la FP fue mayor a los 90 dds (88\%), estadísticamente similares a lo obtenido en semillas tratadas con 3, 6, $9,15,18,27$ y $30 \mathrm{~Gy}$, que en promedio presentaron 42
B)
$\mathrm{DSH}=65.05$
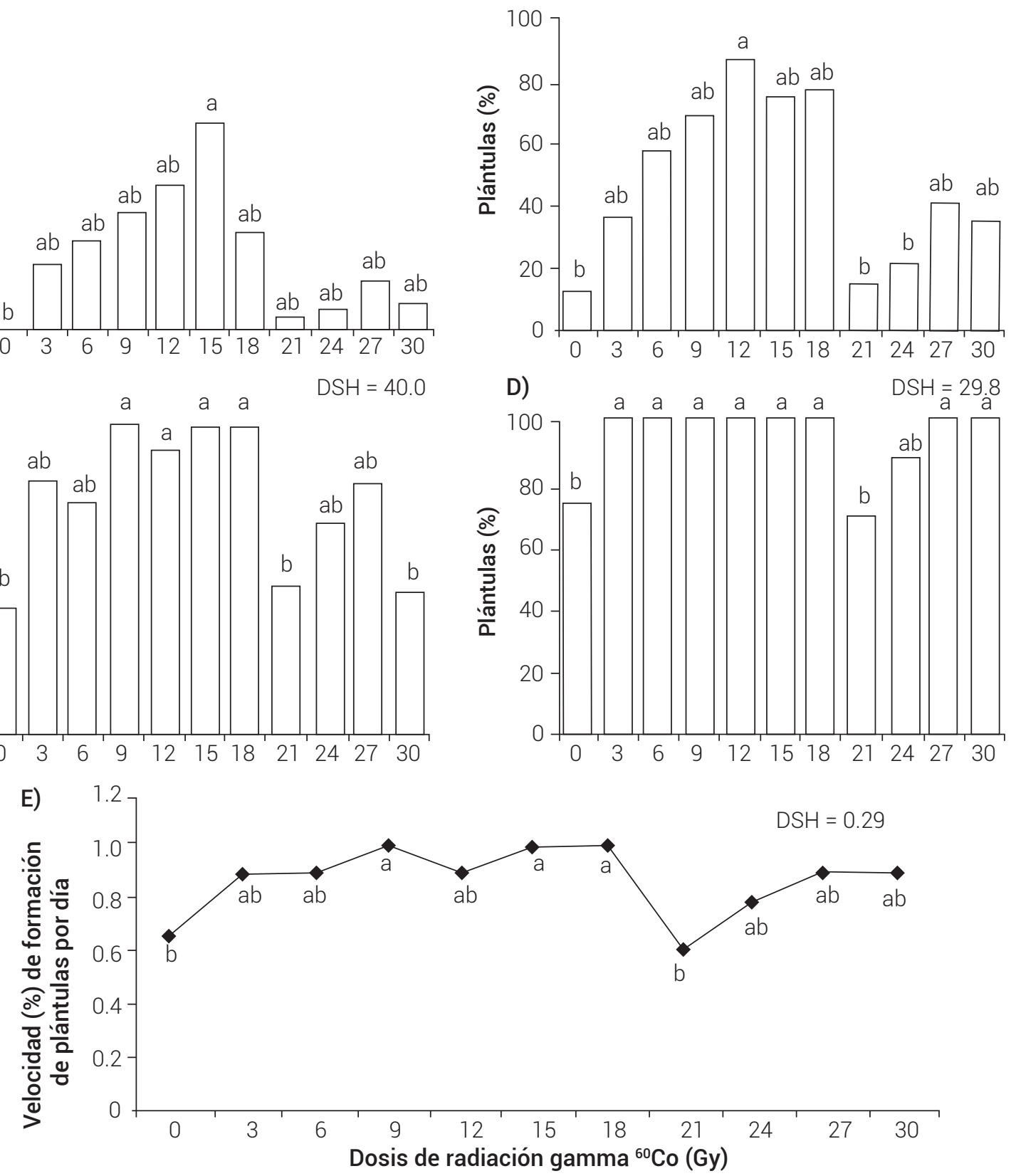

Figura 8. Efecto de la irradiación gamma sobre la formación de plántulas in vitro a partir de semillas de L. autumnalis. A) 80 días después de la siembra (dds), B) 90 dds, C) 100 dds y D) 110 dds. E) velocidad de formación de plántulas. Medias con letras iguales no son estadísticamente diferentes (Tukey, 0.05). 
\% más plántulas que el control (Figura 8B). Este efecto estimulante en la rizogénesis continuó a los 100 dds en las semillas irradiadas con 9 a $18 \mathrm{~Gy}$, que registraron en promedio $57 \%$ más FP que las semillas sin irradiar, mientras que las semillas tratadas con 21 y 30 Gy fueron estadísticamente similares al tratamiento control (Figura 8C). En las semillas del tratamiento control y las tratadas con 21 Gy la FP fue menor (73.5 y $69 \%$ ) a los 110 dds (Figura 8D).

La VFP por día se incrementó en las semillas tratadas con 9, 15 y 18 Gy (0.34 \% más plántulas por día), que en las semillas sin irradiar; estas últimas presentaron valores estadísticamente similares a las tratadas con $21 \mathrm{~Gy}$, que fue la dosis con menor VFP por día (0.62 \%) (Figura 8E).

Estos resultados indican que la radiación gamma ${ }^{60} \mathrm{Co}$ en semillas de $L$. autumnalis en dosis de 3 a 18 Gy estimulan la rizogénesis, y se puede explicar en función de que las bajas concentraciones de radiación estimulan el desarrollo de las plantas; sin embargo, es necesario determinar en cada especie el rango de estimulación, ya que la radiosensibilidad en las plantas varía de acuerdo con el genotipo y la dosis de irradiación absorbida. Por ejemplo en PLBs (cuerpos parecidos a protocormos por sus siglas en inglés) de la orquídea Cymbidium con dosis de 8 Gy se estimula la actividad de reguladores de crecimiento endógenos en los tejidos meristemáticos, lo que incrementa el desarrollo de los PLBS (Kozlowska-Kalisz, 1979). En la germinación de semillas de Triticum durum irradiadas con 20 Gy se encontró un incremento entre 18 y $32 \%$ en el número y longitud de raíces, respectivamente. Este efecto estimulante puede contribuir a mejorar la absorción de agua en condiciones de déficit hídrico (Melki y Marouani, 2010). En semillas de vinca rosa (Catharanthus roseus) irradiadas con 30 Gy se estimuló el número de brotes por plántula (4.4) y la longitud de los brotes $(3.9 \mathrm{~cm})$ (El-Sharnouby et al., 2016).

El uso de radiación gamma ${ }^{60} \mathrm{Co}$ a dosis de 3 Gy indica un efecto radioestimulante de la radiación sobre el proceso de germinación y desarrollo de L. autumnalis. Con esta dosis se redujo el tiempo de formación de promeristemos, hojas y plántulas completas 20, 20 y $10 \mathrm{~d}$ antes que con el tratamiento sin irradiar.

\section{CONCLUSIONES}

La radiación gamma ${ }^{60} \mathrm{Co}$ a dosis bajas estimuló la germinación y aceleró la formación de promeristemos, formación de hojas y formación de plántulas de L. autumnalis durante el cultivo in vitro. La radiación a dosis superiores a 24 Gy inhibe la germinación y el desarrollo de plántulas. La radiación de las semillas con dosis de 9 a 18 Gy aceleró el desarrollo in vitro de plántulas de L. autumnalis.

\section{BIBLIOGRAFÍA}

Aguilar-Morales M. A. y A. L. López-Escamilla (2013) Germinación in vitro de Laelia speciosa (Kunth) Schltr., una herramienta para su conservación ex situ. In: Estudios Científicos en el Estado de Hidalgo y Zonas Aledañas. Vol. II. G. Pulido F. y S. Monks (eds.). Zea Books, University of Nebraska. Lincoln, Nebraska, USA. pp:18-24.

Akshatha and K. R. Chandrashekar (2013) Effect of gamma irradiation on germination, growth and biochemical parameters of Pterocarpus santalinus, an endangered species of Eastern Ghats. European Journal of Experimental Biology 3:266-270.

Akshatha, K. R. Chandrashekar, H. M. Somashekarappa and J. Souframanien (2013) Effect of gamma irradiation on germination, growth, and biochemical parameters of Terminalia arjuna Roxb. Radiation Protection and Environment 36:38-44.

Álvarez F. A., L. Chávez S., R. Ramírez F., R. Pompa B. y W. Estrada P. (2012) Indicadores fisiológicos en plántulas de Solanum lycopersicum L., procedentes de semillas irradiadas con rayos X. Biotecnología Vegetal 12:173-177.

Álvarez F. A., L. Chávez S., R. Ramírez F., W. Estrada P., Y. Estrada L. y A. Maldonado R. (2013) Efecto del tratamiento de semillas con bajas dosis de rayos $X$ en plantas de pimiento (Capsicum annuum $L$.). Nucleus 53:14-19.

Araújo S. S., S. Paparella, D. Dondi, A. Bentivoglio, D. Carbonera and A. Balestrazzi (2016) Physical methods for seed invigoration: advantages and challenges in seed technology. Frontiers in Plant Science 7:646.

Arditti J. (2008) Micropropagation of Orchids. Volume II. 2nd ed. Blackwell Publishing. Oxford, UK. $1537 \mathrm{p}$.

El-Fiki A., G. El Metabteb, A. H. Sayed and M. Adly (2015) Androgenesis induced in Nicotiana alata and the effect of gamma irradiation. Notulae Scientia Biologicae 7:66-71.

Batty A. L., K. W. Dixon, M. Brundrett and K. Sivasithamparam (2001) Constraints to symbiotic germination of terrestrial orchid seed in a Mediterranean bushland. New Phytologist 152:51 1-520.

Billard C. E., C. A. Dalzotto y V. H. Lallana (2014) Desinfección y siembra asimbiótica de semillas de dos especies y una variedad de orquídeas del género Oncidium. Polibotánica 38:145-157.

Chakravarty B. and S. Sen (2001) Enhancement of regeneration potential and variability by $\mathrm{Y}$-irradiation in cultured cells of Scilla indica. Biologia Plantarum 44:189-193.

Cwintal M. and J. Olszewski (2007) Influence of pre-sowing laser stimulation of seeds on photosynthesis and transpiration intensity and on yielding of alfalfa. Acta Agrophysica 9:345-352.

El-Sharnouby M. E., E. Azab and H. E. Abd E. (2016) Performance of Catharanthus roseus plants in response to gamma irradiation. Journal of Biological and Chemical Research 33:130-140.

Francisco N. J. J., A. R. Jiménez-Aparicio, A. De Jesús-Sánchez, M. L. ArenasOcampo, E. Ventura-Zapata y S. Evangelista-Lozano (2011) Estudio de la morfología y aclimatación de plantas de Laelia eyermaniana Rchb. f. generadas in vitro. Polibotánica 32:107-117.

González M. C. y H. D. Nakayama (2015) Radioestimulación de la germinación en Stevia rebaudiana cultivar KH-IAN VC-142 (Eireté) mediante el empleo de rayos gamma ${ }^{60} \mathrm{Co}$. Cultivos Tropicales 36:117-119.

González-Zertuche L. y A. Orozco-Segovia (1996) Métodos de análisis de datos en la germinación de semillas, un ejemplo: Manfreda brachystachya. Boletín de la Sociedad Botánica de México 58:1530.

Hartmann H. T., D. E. Kester, F. T. Davies Jr. and R. L. Geneve (2010) Plant Propagation: Principles and Practices. 8th ed. Prentice Hall. New York, NY. $915 \mathrm{p}$

Kauth P. J., D. Dutra, T. R. Johnson, S. L. Stewart, M. E. Kane and W. Vendrame (2008) Techniques and applications of in vitro orchid seed germination. In: Floriculture, Ornamental and Plant Biotechnology: Advances and Topical Issues. Volume V. J. A. Teixeira da Silva (ed.). Global Science Books. Iselworth, UK. pp:375-391.

Kozlowska-Kalisz J. (1979) The influence of ionizing radiation on biological activity of endogenous growth regulators in orchids/ Cymbidium/ in tissue culture. Acta Horticulturae 91:261-268.

Kumar D. P., A. Chaturvedi, M. Sreedhar, M. Aparna, P. Venu-Babu and R. K. Singhal (2013) Gamma radiosensitivity study on rice (Oryza sativa L.). 
Asian Journal of Plant Science and Research 3:54-68.

Lee E. H. E., A. Laguna C., J. Murguía G., L. Iglesias-Andreu, B. García R., D. Escobedo L., Y. M. Martínez O., F. A. Barredo P. y N. Santana B. (2010) Un protocolo de embriogénesis somática para la regeneración y caracterización in vitro de Laelia anceps ssp. dawsonii. Revista Fitotecnia Mexicana 33:323-332.

Lee Y. I., C. F. Lu, M. C. Chung, E. C. Yeung and N. Lee (2007) Developmental changes in endogenous abscisic acid concentrations and asymbiotic seed germination of a terrestrial orchid, Calanthe tricarinata Lindl. Journal of the American Society for Horticultural Science 132:246-252.

Lee Y. M., H. J. Lee, Y. S. Kim, S. Y. Kang, D. S. Kim, J. B. Kim, J. W. Ahn, B. K. $\mathrm{Ha}$ and S. H. Kim (2016) Evaluation of the sensitivity to ionizing y-radiation of a Cymbidium hybrid. The Journal of Horticultural Science and Biotechnology 91:109-116.

Marcu D., V. Cristea and L. Daraban (2013) Dose-dependent effects of gamma radiation on lettuce (Lactuca sativa var. capitata) seedlings. International Journal of Radiation Biology 89:219-223.

Melki M. and A. Marouani (2010) Effects of gamma rays irradiation on seed germination and growth of hard wheat. Enviromental Chemistry Letters 8:307-310.

Minisi F. A., M. E. El-mahrouk, M. E. F. Rida and M. N. Nasr (2013) Effects of gamma radiation on germination, growth characteristics and morphological variations of Moluccella laevis L. American-Eurasian Journal of Agriculture \& Environmental Sciences 13:696704
Mohammed H. M. A., H. I. Mohamed, L. M. Zaki and A. M. Mogazy (2012) Preexposure to gamma rays alleviates the harmful effect of salinity on cowpea plants. Journal of Stress Physiology \& Biochemistry 8:199-217.

Murashige T. and F. Skoog (1962) A revised medium for rapid growth and bio assays with tobacco tissue cultures. Physiologia Plantarum 15:473-497.

Pierik R. L. M. (1990) Cultivo in vitro de las Plantas Superiores. MundiPrensa. Madrid, España. 326 p.

SAS Institute (2002) SAS/STAT. User's Guide, versión 9.0. Statistical Analysis System Institute. Cary, N. C. USA. 4424 P.

Van-Waes J. M. and P. C. Debergh (1986) Adaptation of the tetrazolium method for testing the seed viability, and scanning electron microscopy study of some Western European orchids. Physiologia Plantarum 66:435-442.

Verdugo G., J. Marchant, M. Cisternas, X. Calderón y P. Peñaloza (2007) Caracterización morfométrica de la germinación de Chloraea crispa Lindl. (Orchidaceae) usando análisis de imagen. Gayana Botánica 64:232-238.

Verma J., K. Sharma, K. Thakur, J. K. Sembi and S. P. Vij (2014) Study on seed morphometry of some threatened Western Himalayan orchids. Turkish Journal of Botany 38:234-251.

Yamazaki J. and K. Miyoshi (2006) In vitro asymbiotic germination of immature seed and formation of protocorm by Cephalanthera falcata (Orchidaceae). Annals of Botany 98:1197-1206. 
